\title{
ANÁLISE DA PARTICIPAÇÃO DAS MULHERES EM CARGOS GERENCIAIS A PARTIR DA PERSPECTIVA DA DIVISẪO SEXUAL DO TRABALHO
}

\author{
Mariana Aparecida Damião*, Lais Silveira Fraga.
}

\section{Resumo}

Durante o período das grandes guerras mundiais no inicio do século $X X$, ocorreu itensa migração de mulheres do trabalho essencialmente doméstico para as fábricas visando a substituição da mão-de-obra masculina que estava a serviço de seu país, ao final deste período as mulheres conquistaram gradualmente seus espaços em ambientes corporativos, público e privado, assumindo cargos de liderança, em especial este trabalho visa o estudo de cargos de gerência, porém a situação da distribuição de mulheres em tal posição hierarquica em relação aos homens não é estatisticamente igualitária segundo dados do indicador 45 do Conjunto Minimo de Indicadores (CMIG) proposto pela Organização das Nações Unidas. O objetivo deste projeto é compreender a eficiência do CMIG45 em relação a exemplificação das desigualdades das mulheres nos cargos de gerência, utilizando como base teorica temas relacionados desigualdade de gênero.

\section{Palavras-chave:}

Divisão sexual do trabalho, cargos de gerência, ambiente corporativo

\section{Introdução}

Cargos gerenciais pertencem a alta hierarquia corporativa e estão associados a liderança, gerenciamento de processos e pessoas. Sendo que, para ocupar estes cargos são necessárias qualificações técnicas, desde formação educacional à desenvoltura profissional, estes pré-requisitos são demonstrado nas vagas, porém essa pesquisa parte do pressuposto da existência de fatores implícitos que denominam o perfil de cargos gerenciais a partir do gênero, visto que, estatisticamente, segundo o indicador 45 do Conjunto mínimo de Indicadores, ou CMIG45, demonstra que os cargos gerenciais são ocupados por menos de $41 \%$ das mulheres no período de 2012 à 2016. Desta forma, o trabalho tem como ponto fundamental contribuir para a análise crítica da eficiência do indicador CMIG45, utilizando como fonte de argumentação teorias explicativas da desigualdade de gênero no mercado de trabalho, sendo estas a divisão sexual do trabalho, segregação horizontal e vertical e teto de vidro.

\section{Resultados e Discussão}

A primeira etapa do projeto foi a realização do levantamento bibliográfico dos principais autores a respeito do tema de divisão sexual do trabalho, Helena Hirata e Daniéle Kergoat são protagonistas no estudo referente a essa segregação existente no mundo do trabalho. Outro tema importante para a elaboração da análise foi a teoria da segregação horizontal e vertical que expõe as divisões do mercado de trabalho em que homens e mulheres são destinados socialmente a determinados cargos e posições hierárquicas. Posteriormente, os dados de 2012 à 2016, do indicador CMIG45 foram compilados e analisados.

Por fim, foi feita a análise crítica da eficiência do indicador a partir das teorias apresentadas.

A figura abaixo demonstra 0 indicador CMIG 45 do período de 2012 a 2016.
Figura 1. Distribuição percentual de homens e mulheres em cargos de gerência no Brasil

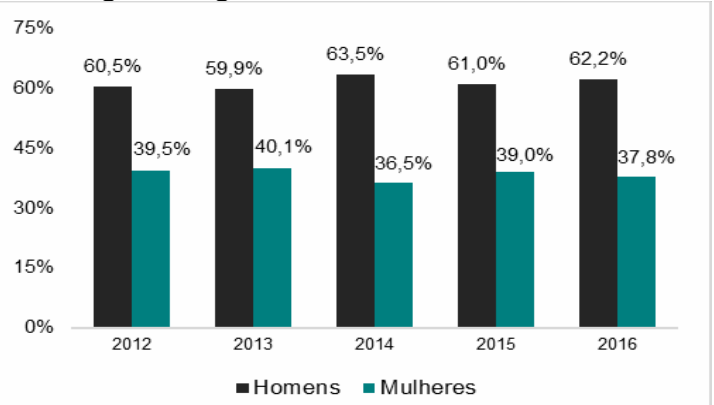

Fonte: IBGE 2018. Gráfico de elaboração própria.

\section{Conclusões}

Ao final do trabalho conclui-se que a apresentação do Conjunto Mínimo de Indicadores, em especial o CMIG45, cumpre sua função social de informação, porém seus dados não são aprofundados no que tange a segregação vertical, pois não apresenta em quais cargos as mulheres estão assumindo funções gerenciais, sendo assim não é possível identificar se o público feminino, apesar de estar assumindo cargos da alta hierarquia ainda permanece em setores econômicos isolados e tipicamente vistos como feminino, ou se estão quebrando barreiras a assumindo áreas em que anteriormente não tinham espaço. Além disso, não há como saber através deste inficador o nível de instrução das mulheres que assumem tal cargo, pois elas podem ter necessitado de anos a mais de estudo em relação aos homens para obter essa função.

HIRATA, Helena; KERGOAT, Danièle. NOVAS CONFIGURAÇÕES DA DIVISÃO SEXUAL DO TRABALHO. Cadernos de Pesquisa, Brasill, v. 37, n. 132, p.595-609. Dezembro de 2007. Disponível em:

<http://www.scielo.br/pdf/cp/v37n132/a0537132.pdf>. Acesso em: 20 agosto de 2018.

ESTATÍSTICAS DE GÊNERO. Instituto Brasileiro de Geografia. 2018 https://www.un-ilibrary.org/economic-and-social-development/data/minimumset-of-gender-indicators/gender-indicators_28bdafa1-

en?parentId=http $\% 3 \mathrm{~A} \% 2 \mathrm{~F} \% 2$ Finstance.metastore.ingenta.com $\% 2$ Fcontent $\% 2$ Fcollection\%2Fe16af645-en 